\title{
Impact of current diet at the risk of non-alcoholic fatty liver disease (NAFLD)
}

\author{
Sebastião Mauro Bezerra DUARTE 1 , José Tadeu STEFANO², Denise Siqueira VANNI ${ }^{3}$, \\ Flair José CARRILHO ${ }^{1,3}$ and Claudia Pinto Marques Souza de OLIVEIRA ${ }^{1,2}$
}

\begin{abstract}
The nonalcoholic fatty liver disease (NAFLD) affects approximately $20 \%-30 \%$ of general population and is even more prevalent among obese individuals. The risk factors mainly associated with NAFLD are diseases related to the metabolic syndrome, genetics and environment. In this review, we provide a literature compilation evaluating the evidence behind dietary components, including calories intake, fat, protein, fibers and carbohydrate, especially fructose which could be a trigger to development and progression of the NAFLD. In fact, it has been demonstrated that diet is an important factor for the development of NAFLD and its association is complex and extends beyond total energy intake.
\end{abstract}

HEADINGS - Non-alcoholic fatty liver disease. Energy intake. Dietary fats. Dietary carbohydrates. Fructose.

\section{INTRODUCTION}

Non-alcoholic fatty liver disease (NAFLD) is one of the most common forms of liver disease primarily related to the progressive increase of obesity in the world. Initially, it was considered to be a liver disease with benign course, however, it is currently known to be a complex disease which involves environmental factors and genetic predisposition $^{(1)}$. NAFLD ranges from simple Steatosis to non-alcoholic steatohepatitis (NASH) that can have different degrees of fibrosis and progress to liver cirrhosis and hepatocellular carcinoma (HCC) in patients with no history of alcoholism ${ }^{(2)}$. Sedentary lifestyle, inadequate intake of foods with high fat and fructose consumption, as well as obesity, metabolic syndrome (MtS), type 2 diabetes mellitus (T2DM), hormonal status and genetic background have been described as responsible for the development of NAFLD ${ }^{(3)}$.

Due to increasing rates of obesity, NAFLD has become more prevalent in all populations, especially in the Western world and has been defined by specialists as the disease of the modern world ${ }^{(4)}$. NAFLD is highly prevalent in the United States and around the world. However, this prevalence differs significantly according to the diagnostic method used and the population studied. As rates of obesity, T2DM and MtS continue to increase, NAFLD can significantly affect health care and the development of long-term complications such as cirrhosis and HCC in the next few years ${ }^{(5)}$.

\section{DIET, NUTRITION INTAKE AND NAFLD}

Balanced and healthy nutrition is one of the main determinants of nutritional status that can prevent many diseases, such as NAFLD.
In fact, an inadequate diet, with a high concentration of saturated fat and cholesterol, simple carbohydrates and xenobiotics, or external contaminants, which lacks in vitamins and fibers, is an important factor for the development of NAFLD. Zelber-Sagi et al. demonstrated that excess caloric consumption, unhealthy diet, sedentary lifestyle leading to obesity and related comorbidities and weight gain per se, even a modest weight gain of $3-5 \mathrm{~kg}$, are leading risk factors for NAFLD, regardless of baseline body mass index $(\mathrm{BMI})^{(6)}$.

Research studies, in order to identify factors related to the development of NAFLD and progression to NASH have discovered that endogenous and exogenous factors [biological origin, synthetic (industrial) or environmental] act as hepatotoxins, including food and water ${ }^{(7,8)}$. Diet is an important factor in the development of NAFLD and this relationship is complex and extends beyond total energy intake. NAFLD patients shown higher energy intake, significantly lower protein and carbohydrate and higher total fat, higher intake of saturated fat, and n-6 consumption was identified compared to controls ${ }^{(9-11)}$.

\section{CALORIES AND FAT}

Studies have analyzed the association between liver fat content and calorie and fat intake ${ }^{(12-14)}$. It has been demonstrated that patients with NAFLD have a significantly higher daily overall calories intake whereas the general dietary composition displays only moderate deviations when compared to healthy controls ${ }^{(9,15)}$.

Moreover, epidemiological studies have demonstrated that NASH patients have a diet richer in saturated fat and cholesterol and poorer in polyunsaturated fatty acids (PUFA) when compared to healthy controls with same age, gender and $\mathrm{BMI}^{(11,16)}$.

Declared conflict of interest of all authors: none
Disclosure of funding: no funding received

${ }^{1}$ Universidade de São Paulo, Faculdade de Medicina, São Paulo, SP, Brasil. ${ }^{2}$ Universidade de São Paulo, Hospital das Clínicas, Laboratório de Gastroenterologia Clínica e Experimental (LIM-07) do Departamento de Gastroenterologia da FMUSP, São Paulo, SP, Brasil. ${ }^{3}$ Universidade de São Paulo, Hospital das Clínicas, Divisão de Gastroenterologia e Hepatologia Clínica e Departamento de Gastroenterologia da FMUSP, São Paulo, SP, Brasil.

Corresponding author: Claudia Pinto Marques de Souza de Oliveira. E-mail: cpm@usp.br 
A recent study of Solon-Biet et al. has revealed that a high fat diet induces hepatic steatosis quickly in ad libitum-fed mice ${ }^{(8)}$.

In obese humans, a diet containing about $55 \%$ of fat increases the amount of intrahepatic triglycerides (TG) by $35 \%$ and the fasting insulin levels are augmented, regardless of body weight ${ }^{(17)}$.

Despite the fact that excessive consumption of saturated fatty acids promotes stress in the endoplasmic reticulum and hepatocyte injury, severe restriction may not be beneficial for patients with NAFLD as previously shown by Zivkovic et al. study. They analyzed dietary patterns with different percentages of total and saturated fat and concluded that, although there was a reduction of low-density lipoprotein cholesterol (LDL), hypolipidic diets also reduced high-density lipoprotein cholesterol levels and increased serum TG and, in individuals with higher percentages of body fat and with insulin resistance (IR), these changes were much more significant after ingestion of very low amounts of total and saturated fats ${ }^{(18)}$.

On the other hand, monounsaturated fatty acids, mainly olive oil, oleaginous (nuts, almonds) and avocado, can be very beneficial for patients with NAFLD as they lower the levels of LDL cholesterol and TG. Diets that range between $20 \%$ and $40 \%$ of the total caloric value in the form of monounsaturated fats have been shown to be beneficial in NAFLD patients, increasing the oxidation of other fatty acids (by the activation of peroxisome proliferator-activated receptors gamma and alpha) and by reduction of lipogenesis (reducing the activation of the sterol regulatory element binding protein $)^{(19)}$.

Low-calorie diets (800 to $1.000 \mathrm{kcal}$ ) were used in an attempt to promote faster and meaningfull weight loss to for a promotion adipose tissue metabolism. A calorie diet derived from low carbohydrate supply (based on $10 \%$ of total calorie in one induction phase and then a gradual increase to $34 \%$ ), was associated with weight reduction when compared to a diet with low lipid content. However, this weight loss was not sustained, and the patient showed difficulty in maintaining his weight in the long term ${ }^{(20)}$. More evidence suggests that limiting carbohydrate intake to less than $20 \mathrm{~g} /$ day as well as maintaining a caloric deficit of $30 \%$, both were beneficial in achieving improvements in NAFLD Activity Score ${ }^{(21)}$, hepatic lipids $^{(22)}$ and serum hepatic enzymes ${ }^{(23)}$. Therefore, a caloric deficit of 500-750 kcal/day is an appropriate therapeutic intervention for NAFLD. It is suggested that women should eat $1200 \mathrm{kcal} /$ day and men $1500 \mathrm{kcal} /$ day and a slightly higher amount of $1500 \mathrm{kcal} /$ day for women and $1800 \mathrm{kcal} /$ day for men might be considered, with adjustments based on their physical activity ${ }^{(15)}$.

\section{CARBOHYDRATE}

During the last decade, dietary habits have evolved to more consumption of sweetened and fatty foods ${ }^{(24)}$. There are substantial evidences which demonstrates that the implication of increased consumption of sugars, specially fructose (sweetened beverage intake), is related to a higher risk of developing T2DM, MtS, NAFLD and cardiovascular (CV) diseases ${ }^{(25)}$

Furthermore, excessive carbohydrate intake may be harmful in patients with NAFLD, and high carbohydrates intake appear to be associated with inflammation and disease progression ${ }^{(26)}$. In fact, low-carbohydrate diets with less than $45 \%$ carbohydrates of their total kcal composition show positive results concerning weight loss, reduction of in intrahepatic TG content and improvement of metabolic parameters among obese individual. However, in an animal model study the maintenance of low carbohydrate diets for extended period stimulated the development of NAFLD and promoted glucose intolerance ${ }^{(27)}$. In this year, Sekkarie et al. evaluated various dietary patterns which were not limited exclusively to reduced added sugars. Such diets turned out to be protective to development and progression of NAFLD ${ }^{(28)}$.

High glycemic index (GI) diets are associated with increased risk of obesity, T2DM, Hyperlipidemia and non-alcoholic fatty liver. High GI may be a good dietary marker of the effect of IR on NAFLD which confirms the importance of choosing a low-GI diet as a tool to prevent NAFLD induced by $\operatorname{IR}^{(29)}$.

In the class of carbohydrates, fructose is perhaps the one that is most related to the progression of NAFLD ${ }^{(30,31)}$. In the 60 s, high fructose corn syrup was inserted in the food industry as a substitute of sugar and the intake increased ${ }^{(32)}$. Over time, fructose was identified as a sugar affecting lipid metabolism by augmenting plasma TG and free fatty acids (FFA). Recently, a cross-sectional study with obese children and adolescents with NAFLD demonstrated that fructose consumption is positively and independently associated with the prevalence of NASH, as diagnosed using NAFLD Activity Score and the fatty liver progression algorithm ${ }^{(33)}$. Another large-scale study with NAFLD patients analyzed the role of overconsumption of fructose-containing diet in the development of this disease. In this study, the authors describe that high daily fructose-containing diet is associated with a higher hepatic fibrosis stage in younger and elderly patients. Surprisingly, this diet was also related to a lower steatosis grade in the older group of patients ${ }^{(34)}$. Volynets et al. have observed that lifestyle intervention focusing on lower fructose intake leads to reduction in hepatic reperfusion and in transaminases levels ${ }^{(35)}$. These studies reinforce fructose consumption as an important preventable risk factor that may lead to advanced NAFLD.

It is known that high sugar consumption upregulates the transport of fructose through the GLUT5 transporter, increasing fructokinase levels in the liver, independently, of energy intake excess ${ }^{(7)}$. Other studies have demonstrated that fructose can also increase TG levels, lead to de novo synthesis of fatty acids, hyperuricemia, hyperferritinemia, and IR increasing the risk of NAFLD ${ }^{(36,37)}$. A study conducted by Sullivan et al. investigated the absorption of fructose in lean children, obese children, and obese children with biopsy proven NAFLD and realized that children with NAFLD may be absorbing and metabolizing fructose more effectively than lean subjects, which could contribute to the pathophysiology of NAFLD. Whether this fact may be related to up-regulation of GLUT5 and fructokinase by previous fructose exposure or whether this is due to genetic/ethnic differences has yet to be determined ${ }^{(38)}$.

On the other hand, high fructose consumption promotes gut inflammation followed by increasing endotoxin release, epithelial dysfunction, and reduction of tight junction proteins independently of the fat content in the diet and energy intake ${ }^{(39)}$. These data illustrate the high impact of nutritional fructose on the intestinal barrier function. An hypothesis exists whether fructose could cause dysbiosis and increase intestinal permeability and endotoxins in the blood ${ }^{(40)}$. Studies have shown a relation between NAFLD-microbiome and diet ${ }^{(33,41,42)}$, leading to intestinal dysbiosis, a scenario that is related to risk factors inducing the development and progression of liver diseases ${ }^{(43,44)}$. A proposed mechanism to explain the relation of a high fructose diet and altered intestinal microbiota leading to increased body fat is the intestinal suppression provoked by fasting induced adipose factor (FIAF). This protein is produced by 
enterocytes and its function is to inhibit lipoprotein lipase (LPL) ${ }^{(45)}$, which when activated, increases the absorption of FFA and TG. These actions are regulated by FIAF. Conclusively, by suppressing FIAF, LPL becomes more active, triggering a greater uptake of short-chain fatty acids and TG; occurs a reduction of oxidation of FFA and augmentation of systemic and peripheral IR. All factors cited contribute to the development of $\mathrm{MtS}$ and to the accumulation of FFA in hepatocytes ${ }^{(18,46,47)}$, leading to several clinically relevant conditions, including NASH and cirrhosis ${ }^{(48)}$ (FIGURE 1). On the other hand, a healthy gut microbiota is maintained by gut bacteria fermentation of non-digestible carbohydrates, this function being also responsible for energy production ${ }^{(49)}$. Moreover, there is evidence that many substances present in fruits, such as flavanols, epicatechin, vitamin $\mathrm{C}$ and other antioxidants may also protect against fructose-induced $\mathrm{MtS}^{(50,51)}$.

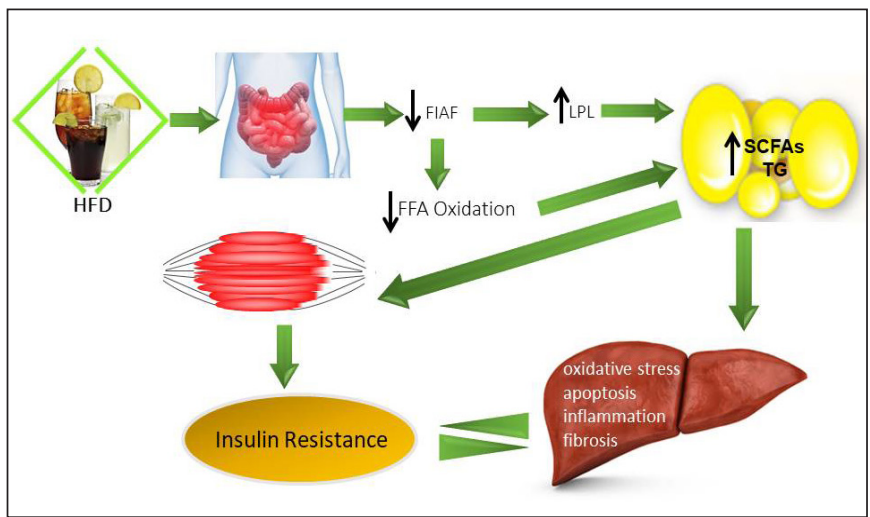

FIGURE 1. Fructose mechanisms mediating development and progression of non-alcoholic fatty liver disease (NAFLD).

HFD: high-fructose diet; FIAF: fasting induced adipose factor; LPL: lipoprotein lipase; FFA: free fatty acids; SCFAs: short-chain fatty acids; TG: triglycerides.

\section{FIBERS}

Fibers can be classified according to their solubility, being the soluble ones represented by pectin (fruits) and gums (oats, barley and legumes like beans, chickpeas, lentils) and insoluble fibers being represented by cellulose (wheat), hemicellulose (grains) and lignin (vegetables) $)^{(52)}$.

A study evaluating dietary patterns in patients with NASH revealed that these patients consumed less carbohydrate, more fat and less fibers than healthy controls ${ }^{(10)}$. A review of the therapeutic effects of dietary fibers, especially derived from whole grains, demonstrated the benefits of its consumption and the reduction of comorbidities associated with MtS and NAFLD. In addition to reduction of liver fat, fibers derived from whole grains could also reduce inflammation ${ }^{(53,54)}$.

\section{FISH OIL}

A recent research has suggested that PUFA administration improves plasma lipid profile and may be useful in the treatment of NAFLD ${ }^{(55)}$. The PUFA's precursor is $\alpha$-linoleic acid (ALA) and its metabolites are, eicosapentaenoic acid (EPA) and docosahexaenoic acid (DHA). These acids are detected in fish that synthesize PUFA from ingestion of marine plants. Some studies have shown that PUFA have a protective role in the development and progression of
NAFLD $^{(56,57)}$. EPA and DHA are able to prevent and reverse liver disease in animal models of obesity ${ }^{(56)}$ and in humans, obesity and NAFLD, are negatively associated with the long-chain omega-3 fatty acid ${ }^{(58,59)}$.

Early interest in PUFA supplements as possible therapy for NASH can be hypothesized considering the close association between MtS, CV disease, fatty liver and reports of CV benefits of omega-3-rich foods ${ }^{(60,61)}$. A meta-analysis presented by Parker et al. showed that dietary $\omega-3$ PUFA supplements ameliorated the hepatic steatosis and liver injury in adult NAFLD patients ${ }^{(62)}$. Yuan et al. demonstrated that supplementation of $\omega-3$ PUFA reduced steatosis and hepatic inflammation in animal models with hepatic TG accumulation, inflammation and fibrogenesis induced by chronic high-fat diet ${ }^{(63)}$. Our group have performed a controlled randomized trial evaluating the PUFA supplementation and demonstrated significant impact on lipid profile in NASH patients by increasing plasma $\omega$-3 PUFA levels, decreasing levels of the potentially proinflammatory $\omega-6$ arachidonic acid (AA), and decreasing serum TG levels. Nonetheless, no significant improvement in NAFLD Activity Score was verified ${ }^{(64)}$.

Noticeable heterogeneity was observed in the trials including dose, formulation and time of PUFA supplementation for the treatment of NAFLD. None of the studies have shown improvement in key prognostic histological features such as fibrosis. One study using biopsy as the measure of fat content reported no change in steatosis after 12 months of synthetic EPA supplementation (up to $2.700 \mathrm{mg} /$ day) compared to placebo treated subjects ${ }^{(65)}$. In contrast, another trial has reported significant hepatic fat reduction after 15-18 months of $4.000 \mathrm{mg} /$ day of a synthetic mixture of EPA and DHA supplementation compared to placebo ${ }^{(66)}$. Similarly, Argo et al. have demonstrated that 12 months supplementation of 3.000 $\mathrm{mg}$ /day of a fish oil derived mixture of EPA and DHA versus soybean oil placebo, reduced liver fat in magnetic resonance imaging. However, the effect was significantly less evident in patients who lost a modest amount of weight during the study period ${ }^{(67)}$. While there appears to be greater evidence that regular consumption of PUFA has metabolic benefit, the effect of additional oily fish or fish oil supplementation in NAFLD is uncertain and current optimal dose is still unknown. Even though some studies have shown consistent improvement in liver fat content, recent trials have not shown a significant benefit in liver histology or fibrosis.

Several therapeutic approaches are used in the treatment of NAFLD and NASH but it is confirmed that the most effective treatment is lifestyle change such as regular physical activity and weight reduction ${ }^{(68-70)}$, however, very fast weight loss up to $1.6 \mathrm{~kg}$ per week may aggravate the inflammatory status of individuals with NAFLD ${ }^{(71)}$. In this case, the most important is moderate weight loss and mainly prioritize the correct choice of dietary nutrients. Although low-calorie diets are effective approaches to improve NAFLD ${ }^{(23,72)}$, it has been shown that the dietary pattern of Mediterranean countries has been the best strategy for NAFLD management ${ }^{(73,74)}$. In the following chapters, we will describe some dietary patterns such as protein diet, vegetarian diet and Mediterranean diet, as well as some foods like coffee and dark chocolate as beneficial components in NAFLD.

\section{PROTEIN DIET}

There are few studies which demonstrate any relation between protein intake and NAFLD. Little is known about the effect of 
the quantity, quality and composition of dietary proteins on the development and treatment of NAFLD. Whereas protein deficiency malnutrition can cause steatosis, and excessive protein intake can lead to glomerular sclerosis, hypertension in intrarenal capillaries as well as malfunction of the kidneys in individuals vulnerable to kidney disease ${ }^{(18)}$. Limited evidence suggests that a high protein diet could be effective to treat NAFLD because of increase in energy expenditure and hepatic lipid oxidation, as liver catabolism of ingested amino acids is an intense energy process ${ }^{(75)}$. In obese sedentary women, short-term protein supplementation was advantageous for hepatic steatosis and lipid profile ${ }^{(76)}$. Soy protein has also been successfully implicated in this same clinical scenario, however the functional properties of soybeans related to the amino acid profile, polyunsaturated fatty acids and isoflavonoids were the focus on study, not the protein intake ${ }^{(77)}$. As a matter of fact, soy protein has been advocated as ideal for NAFLD patients based on animal studies. Clinical evaluations are insufficient in most protocols, however weight loss tends to be prominent ${ }^{(78)}$.

There are recent evidences that a high protein, low calorie diet is associated with improvement of lipid profile, glucose homeostasis and liver enzymes ${ }^{(23)}$ and findings are consistent with the wellestablished principle of calorie restriction in the management of $\mathrm{MtS}$ components and liver histology ${ }^{(79,80)}$.

Studies comparing different diets for NASH treatment are still scarce. In the largest randomized trial up until now, 170 overweight adults were enrolled and followed for a period of six months. They were divided in three groups of diet: high in protein, low in fat and low in carbohydrate content. Results were equivalent among groups which demonstrated: reductions in intrahepatic fat, alanine aminotransferase (ALT), visceral adiposity and total weight as well as changes in whole body insulin sensitivity ${ }^{(22)}$.

A recent study showed that whey protein supplementation $(60 \mathrm{~g} /$ day) for 30 days, without energy restriction, decreased intrahepatic lipids. Despite stability of BMI, body fat mass had diminished. Additional metabolic advantages were identified in plasma lipids levels, however it was not seen in glucose homeostasis markers ${ }^{(76)}$. Two short-term protocols with protein supplementation showed also improvement in hepatic fat content with a stable body weight ${ }^{(81,82)}$.

Ideal dietary intake is intended to guarantee both moderate caloric restriction and adequate protein intake. According to European Association for the Study of the Liver (EASL) guidelines, although good quality data are lacking, particular attention must be paid to the protein intake needed to maintain muscle mass, because of the potential risk of exacerbating sarcopenia during weight loss interventions ${ }^{(83)}$.

\section{VEGETARIAN DIET}

The benefits of a vegetarian healthy diet have been reported over the last few years, but there are still few randomized controlled trials $^{(84,85)}$. Recently, evidence has shown that the consumption of vegetables and fruits protects against metabolic diseases such as $\mathrm{T}^{2} \mathrm{DM}^{(86)}, \mathrm{CV}$ disease ${ }^{(87)}$ and NAFLD ${ }^{(88)}$. These aliments are rich in fiber and antioxidant vitamins and their caloric density is low, which favors a higher daily energy consumption, fastly promoting satiety which is sustained for a longer time. All of these facilitates the management of weight loss ${ }^{(89,90)}$.

A meta-analysis conducted by Yang Y et al. have demonstrated that the consumption of vegetables, but not fruit, was associated with lower risk of $\mathrm{HCC}^{(91)}$. These different effects of vegetables and fruit might be explained by differences in their nutrient compositions. Fruits contain more calories and antioxidants, such as vitamin A, C, E and carotenoids. Whether vegetables not only provide dietary fiber and vitamins A and E, but they are also sources of phytochemicals (folate, tocopherols, and carotenoids) which have shown anti-tumor activities in different diseases ${ }^{(92,93)}$.

Patients with NAFLD are advised to adhere to several dietary recommendations such as avoiding simple carbohydrates, saturated fats, and sweetened drinks as well as consuming diets rich in fruits and vegetables ${ }^{(70,94,95)}$. Studies have demonstrated that due to a high content of fiber, phytochemicals, and antioxidants in fruits and vegetables, the high intake of these food groups showed protective effects on NAFLD. Phytochemicals and antioxidants are anti-inflammatory compounds and can prevent developing hepatic steatosis and maintaining blood glucose, insulin and free fatty acids within laboratory reference ranges ${ }^{(96,97)}$. In a cross-sectional study, non-starchy vegetables consumption had been associated with lower liver fat deposition, and dark green or bright orange/yellow vegetables intake had been associated with lower visceral fat and improved insulin sensitivity ${ }^{(88)}$. Other positive effects attributed to fruits and vegetables consumption are related to antioxidants such as the polyphenols which are present in these foods ${ }^{(98)}$. Polyphenols display beneficial effects on metabolic homeostasis and exert antiinflammatory and anti-fibrotic effects, inhibit de novo lipogenesis and stimulate $\beta$-oxidation in the NAFLD models ${ }^{(89)}$.

Although fruits and vegetables have so many benefits, their consumption were lower in NAFLD patients compared with healthy subjects or recommended amounts in reviewed studies ${ }^{(11,99,100)}$.

\section{MEDITERRANEAN DIET}

The traditional Mediterranean diet (MD) is the most frequently studied diet in NAFLD scenario. Its plays a beneficial role in metabolic profile ${ }^{(101)}$ and has been shown to reduce the risk of CV disease ${ }^{(102)}$ and T2DM ${ }^{(103)}$, two highly relevant outcomes in NAFLD patients.

The main characteristics of the MD is a large intake of fruits, vegetables, whole grains, nuts, olive oil, fish and poultry and low consumption of dairy products, processed foods, saturated fats, red meats, foods high in sugar and moderate alcohol intake, usually red wine consumed with meals ${ }^{(104-106)}$. Several clinical and experimental studies have shown that the MD and the higher PUFA intake reduce hepatic triglyceride content, increase insulin sensitivity, and improve $\mathrm{NASH}^{(61,67,107,108)}$ and has been consistently beneficial with respect to CV risk ${ }^{(109,110)}$. Estruch $\mathrm{R}$ et al., observed that consumption of extra virgin olive oil or nuts in the MD resulted in a substantial reduction in the risk of $\mathrm{CV}$ events among high-risk people (age 55+, smokers, hypertensive patients and type 2 diabetics $)^{(102)}$.

The MD is also characterized by reduced carbohydrate intake (40\% of calories), especially reduced sugars (sucrose and fructose) and refined carbohydrates, which may be partly responsible for its beneficial effect on NAFLD ${ }^{(111)}$. Reduction in fructose intake from artificially sweetened beverages improved MtS in obese individuals, regardless of dietary fruit consumption ${ }^{(112)}$. The recommendation of fruit consumption in the MD to be given safely due to the various healthy nutrients present fruit such as fiber and antioxidants.

Although the MD recommends drinking wine in moderation, it is unclear whether NAFLD patients should adopt this recommendation. Patients with cirrhosis should avoid alcohol, as any regular alcohol consumption puts them at higher risk of developing 
$\mathrm{HCC}^{(113)}$. However, it remains uncertain about moderate alcohol consumption (up to two doses per day) in patients without cirrhosis. The specific protective effect for wine may be due to the phytosterols found in grapes $^{(114)}$

Adherence to the MD pattern leads to a significant decrease in liver fat in overweight and NAFLD patients ${ }^{(115)}$ with or without $\mathrm{T}_{2} \mathrm{DM}^{(116,117)}$ and have been included as therapeutic recommendations in the recent European guideline for the treatment of NAFLD ${ }^{(118)}$.

\section{COFFEE AND DARK CHOCOLATE}

The coffee is one of the most consumed beverages in the world and can have beneficial effects on the liver. Coffee consumption has been associated with reduced liver enzymes including ALT, aspartate aminotransferase (AST) and gamma glutamyltransferase ${ }^{(119,120)}$. Coffee intake has also been associated with lower severity of liver disease and lower rates of liver disease progression ${ }^{(121)}$. In addition, drinking coffee was inversely related to alcoholic and nonalcoholic liver cirrhosis in case-control studies ${ }^{(122,123)}$ and alcoholic cirrhosis in prospective study ${ }^{(124)}$. Epidemiological studies have suggested that coffee consumption is protective against chronic liver disease and reduces the risk of developing $\mathrm{HCC}^{(125-127)}$. Experimental data have shown potential beneficial effects on the liver following consumption of various coffee components, including caffeine ${ }^{(128)}$, coffee oils (kahweol and cafestol) ${ }^{(129)}$ and aromatic extracts isolated from coffee beans ${ }^{(130)}$.

Caffeine is not only associated with a decreased of various liver diseases, but its consumption may also decrease mortality ${ }^{(131)}$. There is evidence that daily consumption of two to three cups of coffee has significant health benefits. Thus, coffee appears to have "hepatoprotective" health benefits ${ }^{(132)}$. Coffee is made up of more than 100 compounds, any of which may be responsible for their beneficial effects, so it is possible that the described hepatic benefits come from a synergistic effect of multiple compounds and not a particular compound ${ }^{(133)}$. It is important to mention that different types of coffee may show different effects on liver disease. Studies show that filtered coffee has a hepatoprotective role while unfiltered coffee showed a potentially deleterious effect ${ }^{(125,134)}$. Perhaps this difference is due to the presence of kahweol and cafestol which are released from ground coffee beans but removed by paper filters ${ }^{(135)}$. Anty et al. showed that espresso coffee had no beneficial effect on liver disease, particularly NAFLD, but the authors postulated that espresso coffee may not have been beneficial due to the addition of sucrose ${ }^{(133)}$.

Although so many studies show that coffee consumption has beneficial effects, a recent study suggests that coffee intake was not associated with lower chances of hepatic steatosis in NASH or alcoholic disease ${ }^{(136)}$. Due to divergences in scientific evidence on coffee consumption and prevention or treatment of NAFLD, further longitudinal and interventionist studies are needed for this evidence.

Like coffee, dark chocolate has antioxidant components, like to epicatequina, that can play a therapeutic role in NAFLD. Consumption of dark chocolate is associated with improved CV risk by reducing lipid peroxidation ${ }^{(137)}$. Loffredo L et al. showed that $40 \mathrm{~g}$ of dark chocolate supplementation per day reduced Nicotinamide adenine dinucleotide phosphate (NOX) oxidase in NASH patients ${ }^{(138)}$. In addition, the same authors recently published that the cocoa polyphenols improve endothelial function via Nox2 down-regulation in NASH patients ${ }^{(139)}$. NOX is considered the major cellular source of reactive oxygen species in humans ${ }^{(140)}$ and its activation has been associated with liver damage ${ }^{(141)}$.

The supplementation of dark chocolate associated with cocoa and almonds in overweight and obese individuals resulted in favorable effects on lipid and lipoprotein profiles such as LDL, however, dark chocolate and cocoa alone had no effect on vascular health markers and oxidative stress ${ }^{(142)}$. A recent study showed a prebiotic effect of dark chocolate in overweight individuals. Supplementation of $10 \mathrm{~g}$ dark chocolate per day increased the abundance of symbiotic bacteria such as lactobacillus ${ }^{(143)}$. This modulation in the intestinal microbiota may be a potential therapeutic effect for NAFLD in the future.

\section{RECOMMENDATIONS FOR TREATMENT OF NAFLD}

Lifestyle modification, including diet, exercise, and weight loss has been recommended to treat NAFLD patients. Excessive energy intake, particularly in the form of complex carbohydrates, increased fructose consumption, saturated fats and industrialized products, combined with a sedentary lifestyle have contributed to dysregulated metabolism and consequently leading to obesity and NAFLD. According to American Association for the Study of Liver Diseases and EASL guidelines a combination of a hypocaloric diet (daily reduction by $500-1.000 \mathrm{kcal}$ ) and moderate-intensity exercise is likely to provide the best likelihood to lose $7 \%-10 \%$ total weight and sustaining weight loss over time $\mathrm{e}^{(118,144)}$

The EASL guidelines recommended adherence to the Mediterranean diet with low-to-moderate fat and moderate-to-high carbohydrate intake and Low-carbohydrate ketogenic diets or high-protein. Besides this, it is suggested avoid fructose-containing beverages and foods. Additionally, recommended to moderate alcohol intake, strictly keep alcohol below the risk threshold (30 g/day, men; $20 \mathrm{~g} /$ day, women $)^{(118)}$. Coffee shown the protective in NAFLD, as in liver disease of other etiologies, reducing histological severity and liver-related outcomes ${ }^{(126)}$. There are no liver-related limitations for coffee drinking ${ }^{(118)}$

The protein intake is essential to improves $\mathrm{CV}$ risk factors and insulin sensitivity and decreases the risk of morbidity and mortality $^{(74)}$. The EASL Clinical Practice Guidelines on nutrition in chronic liver disease recommended the optimal daily protein intake should not be lower than $1.2-1.5 \mathrm{~g} / \mathrm{kg}$ actual body weight $/ \mathrm{day}^{(83)}$.

Omega-3 fatty acids should not be used as a specific treatment of NAFLD or NASH, however, they might be considered to treat hypertriglyceridemia in NAFLD patients ${ }^{(144)}$.

Nowadays, pharmacological treatment of NAFLD is still limited and it is mostly based on the treatment of comorbidities. The drug therapy is based on understanding the pathogenesis of the disease, focusing on IR, oxidative stress, inflammatory process and on the mechanism involved directly and indirectly in the progression of fibrosis.

Antioxidant drugs have been investigated as promising treatments for NASH. Vitamin E administered at a daily dose of 800 IU/day have improved liver histology in nondiabetic adults with biopsy-proven NASH and therefore might be considered for this population $^{(145)}$. However, vitamin $\mathrm{E}$ is not recommended to treat NASH in diabetic patients, NAFLD without liver biopsy, NASH cirrhosis, or cryptogenic cirrhosis ${ }^{(144)}$.

$\mathrm{N}$-acetylcysteine (NAC), a glutathione precursor, leads to the reduction of oxidative stress. Some studies using NAC and 
metformin have shown benefit in hepatic histology ${ }^{(146,147)}$. International guidelines recommend thiazolidinediones (pioglitazone) and glucagon-like peptide-1 analogues (liraglutide) showing significant results in enzymes and hepatic histology ${ }^{(118,144)}$.

For patients with severe obesity $\left(\mathrm{BMI}>35 \mathrm{~kg} / \mathrm{m}^{2}\right)$ and $\mathrm{NASH}$, bariatric surgery is an option to be considered, as in most of these patients diet and physical activity are not effective and are not capable of achieving significant and sustained weight loss. The metabolic surgery improving obesity and diabetes, reduces liver fat and is likely to reduce NASH progression ${ }^{(148)}$. Prospective data have shown an improvement in all histological lesions of NASH, including fibrosis ${ }^{(149)}$.

More recently, it has been shown that unbalance of the intestinal microbiota (dysbiosis) and its bacterial metabolites may also contribute to the development of NAFLD. Evidence have shown that increased intestinal permeability leads to bacterial translocation and the endotoxins produced by these bacteria increases LPL activity. This augmentation of LPL activity promotes de novo fatty acid synthesis, TG production ${ }^{(150)}$ and activation of inflammatory Toll-like receptors in hepatocytes ${ }^{(151)}$. Current studies have shown that the use of pre- and probiotics can modulate intestinal microbiota in several diseases ${ }^{(152)}$, including NAFLD ${ }^{(153,154)}$. In addition, probiotics improved intestinal microbiota composition associated with a reduction in liver inflammation, diminished LPS concentrations, reduction of aminotransferases concentrations ${ }^{(155,156)}$, improvement of inflammatory factors ${ }^{(157,158)}$ and also improvement of metabolic parameters of NAFLD, such as, visceral fat, total cholesterol and $\mathrm{IR}^{(159)}$.

It is important to note that, although there are several studies showing efficacy of pre- and probiotic supplementation in NAFLD patients, the guidelines do not recommend their supplementation as NAFLD/NASH treatment.

\section{Authors' contribution}

Oliveira CPMS was responsible for study design. Duarte SMB, Stefano JT, Vanni DS writing the manuscript. Stefano JT, Carrilho FJ and Oliveira CPMS helped on the revision of the manuscript.

\section{Orcid}

Sebastião Mauro Bezerra Duarte: 0000-0001-6988-7701.

Jose Tadeu Stefano: 0000-0002-0218-1920.

Denise Siqueira Vanni: 0000-0002-2624-5116.

Flair José Carrilho: 0000-0002-7682-3105.

Claudia P. Oliveira: 0000-0002-2848-417X.

Duarte SMB, Stefano JT, Vanni DS, Carrilho FJ, Oliveira CPMS. Impacto da dieta usual no risco de doença hepática gordurosa não alcoólica (DHGNA). Arq Gastroenterol. 2019;56(4):431-9.

RESUMO - A doença hepática gordurosa não alcoólica (DHGNA) afeta aproximadamente de 20\% a 30\% da população geral sendo prevalente entre os indivíduos obesos. Os fatores de risco associados à DHGNA são: doenças relacionadas à síndrome metabólica, fatores genéticos e meio ambiente. Nesta revisão, fornecemos uma compilação bibliográfica avaliando como as evidências relacionadas aos componentes da dieta, incluindo ingestão calórica, de gorduras, de proteínas, de fibras e de carboidratos, especialmente a frutose, poderiam ser um estímulo para o desenvolvimento e progressão da DHGNA. Foi demonstrado que a dieta é um fator importante para o desenvolvimento da DHGNA e sua associação se estende além do consumo total de calorias.

DESCRITORES - Hepatopatia gordurosa não alcoólica. Ingestão de energia. Gorduras na dieta. Carboidratos da dieta. Frutose.

\section{REFERENCES}

1. Atabek ME. Non-alcoholic fatty liver disease and metabolic syndrome in obese children. World J Gastroenterol. 2011;17:4445-6.

2. Harrison B, Thomson W, Symmons D, Ollier B, Wiles N, Payton T, et al. The influence of HLA-DRB1 alleles and rheumatoid factor on disease outcome in an inception cohort of patients with early inflammatory arthritis. Arthritis Rheum. 1999; 42:2174-83

3. Murphy EF, Cotter PD, Hogan A, O'Sullivan O, Joyce A, Fouhy F, et al. Divergent metabolic outcomes arising from targeted manipulation of the gut microbiota in diet-induced obesity. Gut. 2013;62:220-6.

4. Angelico F, Del Ben M, Conti R, Francioso S, Feole K, Fiorello S, et al. Insulin resistance, the metabolic syndrome, and nonalcoholic fatty liver disease. J Clin Endocrinol Metab. 2005;90:1578-82.

5. Sayiner M, Koenig A, Henry L, Younossi ZM. Epidemiology of Nonalcoholic Fatty Liver Disease and Nonalcoholic Steatohepatitis in the United States and the Rest of the World. Clin Liver Dis. 2016;20:205-14.

6. Zelber-Sagi S, Lotan R, Shlomai A, Webb M, Harrari G, Buch A, et al. Predictors for incidence and remission of NAFLD in the general population during a seven-year prospective follow-up. J Hepatol. 2012;56:1145-51.

7. Roncal-Jimenez CA, Lanaspa MA, Rivard CJ, Nakagawa T, Sanchez-Lozada LG, Jalal D, et al. Sucrose induces fatty liver and pancreatic inflammation in male breeder rats independent of excess energy intake. Metabolism. 2011;60:1259-70.

8. Solon-Biet SM, McMahon AC, Ballard JW, Ruohonen K, Wu LE, Cogger VC, et al. The ratio of macronutrients, not caloric intake, dictates cardiometabolic health, aging, and longevity in ad libitum-fed mice. Cell Metab. 2014;19:418-30.

9. Wehmeyer MH, Zyriax BC, Jagemann B, Roth E, Windler E, Schulze Zur Wiesch $\mathrm{J}$, et al. Nonalcoholic fatty liver disease is associated with excessive calorie intake rather than a distinctive dietary pattern. Medicine (Baltimore). 2016;95:e3887.
10. Cortez-Pinto H, Jesus L, Barros H, Lopes C, Moura MC, Camilo ME. How different is the dietary pattern in non-alcoholic steatohepatitis patients? Clin Nutr. 2006;25:816-23.

11. Musso G, Gambino R, De Michieli F, Cassader M, Rizzetto M, Durazzo M, et al. Dietary habits and their relations to insulin resistance and postprandial lipemia in nonalcoholic steatohepatitis. Hepatology. 2003;37:909-16.

12. Koch M, Borggrefe J, Barbaresko J, Groth G, Jacobs G, Siegert S, et al. Dietary patterns associated with magnetic resonance imaging-determined liver fat content in a general population study. Am J Clin Nutr. 2014;99:369-77.

13. Mollard RC, Sénéchal M, MacIntosh AC, Hay J, Wicklow BA, Wittmeier KD, et al. Dietary determinants of hepatic steatosis and visceral adiposity in overweight and obese youth at risk of type 2 diabetes. Am J Clin Nutr. 2014;99:804-12.

14. Sathiaraj E, Chutke M, Reddy MY, Pratap N, Rao PN, Reddy DN, et al. A case-control study on nutritional risk factors in non-alcoholic fatty liver disease in Indian population. Eur J Clin Nutr. 2011;65:533-7.

15. Marchesini G, Petta S, Dalle Grave R. Diet, weight loss, and liver health in nonalcoholic fatty liver disease: Pathophysiology, evidence, and practice. Hepatology. 2016;63:2032-43

16. Toshimitsu K, Matsuura B, Ohkubo I, Niiya T, Furukawa S, Hiasa Y, et al. Dietary habits and nutrient intake in non-alcoholic steatohepatitis. Nutrition. 2007;23:46-52.

17. Westerbacka J, Lammi K, Häkkinen AM, Rissanen A, Salminen I, Aro A, et al Dietary fat content modifies liver fat in overweight nondiabetic subjects. J Clin Endocrinol Metab. 2005;90:2804-9.

18. Zivkovic AM, German JB, Sanyal AJ. Comparative review of diets for the metabolic syndrome: implications for nonalcoholic fatty liver disease. Am J Clin Nutr. 2007:86:285-300. 
19. Antonucci L, Porcu C, Iannucci G, Balsano C, Barbaro B. Non-Alcoholic Fatty Liver Disease and Nutritional Implications: Special Focus on Copper. Nutrients. 2017;9(10).

20. Sacks FM, Bray GA, Carey VJ, Smith SR, Ryan DH, Anton SD, et al. Comparison of weight-loss diets with different compositions of fat, protein, and carbohydrates. N Engl J Med. 2009;360:859-73.

21. Tendler D, Lin S, Yancy WS, Mavropoulos J, Sylvestre P, Rockey DC, et al. The effect of a low-carbohydrate, ketogenic diet on nonalcoholic fatty liver disease: a pilot study. Dig Dis Sci. 2007;52:589-93.

22. Haufe S, Engeli S, Kast P, Böhnke J, Utz W, Haas V, et al. Randomized comparison of reduced fat and reduced carbohydrate hypocaloric diets on intrahepatic fat in overweight and obese human subjects. Hepatology. 2011;53:1504-14.

23. Bezerra Duarte SM, Faintuch J, Stefano JT, Sobral de Oliveira MB, de Campos Mazo DF, Rabelo F, et al. Hypocaloric high-protein diet improves clinical and biochemical markers in patients with nonalcoholic fatty liver disease (NAFLD). Nutr Hosp. 2014;29:94-101.

24. Brownell KD, Farley T, Willett WC, Popkin BM, Chaloupka FJ, Thompson JW, et al. The public health and economic benefits of taxing sugar-sweetened beverages. N Engl J Med. 2009;361:1599-605.

25. Malik VS, Popkin BM, Bray GA, Després JP, Hu FB. Sugar-sweetened beverages, obesity, type 2 diabetes mellitus, and cardiovascular disease risk. Circulation. 2010;121:1356-64.

26. Boulangé CL, Neves AL, Chilloux J, Nicholson JK, Dumas ME. Impact of the gut microbiota on inflammation, obesity, and metabolic disease. Genome Med. 2016;8:42.

27. Schugar RC, Crawford PA. Low-carbohydrate ketogenic diets, glucose homeostasis, and nonalcoholic fatty liver disease. Curr Opin Clin Nutr Metab Care 2012;15:374-80.

28. Sekkarie A, Welsh JA, Vos MB. Carbohydrates and diet patterns in nonalcoholic fatty liver disease in children and adolescents. Curr Opin Clin Nutr Metab Care. 2018;21:283-8

29. Scribner KB, Pawlak DB, Ludwig DS. Hepatic steatosis and increased adiposity in mice consuming rapidly vs. slowly absorbed carbohydrate. Obesity (Silver Spring). 2007;15:2190-9.

30. Fedirko V, Lukanova A, Bamia C, Trichopolou A, Trepo E, Nöthlings U, et al Glycemic index, glycemic load, dietary carbohydrate, and dietary fiber intake and risk of liver and biliary tract cancers in Western Europeans. Ann Oncol. 2013;24:543-53.

31. Stanhope KL, Havel PJ. Fructose consumption: considerations for future research on its effects on adipose distribution, lipid metabolism, and insulin sensitivity in humans. J Nutr. 2009;139:1236S-41S

32. White JS. Challenging the fructose hypothesis: new perspectives on fructose consumption and metabolism. Adv Nutr. 2013;4:246-56.

33. Mosca A, Nobili V, De Vito R, Crudele A, Scorletti E, Villani A, et al. Serum uric acid concentrations and fructose consumption are independently associated with NASH in children and adolescents. J Hepatol. 2017;66:1031-6.

34. Abdelmalek MF, Suzuki A, Guy C, Unalp-Arida A, Colvin R, Johnson RJ, et al. Increased fructose consumption is associated with fibrosis severity in patients with nonalcoholic fatty liver disease. Hepatology. 2010;51:1961-71.

35. Volynets V, Machann J, Küper MA, Maier IB, Spruss A, Königsrainer A, et al A moderate weight reduction through dietary intervention decreases hepatic fat content in patients with non-alcoholic fatty liver disease (NAFLD): a pilot study. Eur J Nutr. 2013;52:527-35.

36. Ouyang X, Cirillo P, Sautin Y, McCall S, Bruchette JL, Diehl AM, et al. Fructose consumption as a risk factor for non-alcoholic fatty liver disease. J Hepatol. 2008;48:993-9.

37. Zelber-Sagi S, Nitzan-Kaluski D, Goldsmith R, Webb M, Blendis L, Halpern $\mathrm{Z}$, et al. Long term nutritional intake and the risk for non-alcoholic fatty liver disease (NAFLD): a population based study. J Hepatol. 2007:47:711-7.

38. Sullivan JS, Le MT, Pan Z, Rivard C, Love-Osborne K, Robbins K, et al. Oral fructose absorption in obese children with non-alcoholic fatty liver disease. Pediatr Obes. 2015;10:188-95.

39. Volynets V, Louis S, Pretz D, Lang L, Ostaff MJ, Wehkamp J, et al. Intestinal Barrier Function and the Gut Microbiome Are Differentially Affected in Mice Fed a Western-Style Diet or Drinking Water Supplemented with Fructose. J Nutr. 2017;147:770-80.

40. Machado MV, Cortez-Pinto H. Diet, Microbiota, Obesity, and NAFLD: A Dangerous Quartet. Int J Mol Sci. 2016;17:481

41. Shimony MK, Schliep KC, Schisterman EF, Ahrens KA, Sjaarda LA, Rotman Y, et al. The relationship between sugar-sweetened beverages and liver enzymes among healthy premenopausal women: a prospective cohort study. Eur J Nutr. 2016;55:569-76.

42. Paolella G, Mandato C, Pierri L, Poeta M, Di Stasi M, Vajro P. Gut-liver axis and probiotics: their role in non-alcoholic fatty liver disease. World J Gastroenterol. 2014;20:15518-31.
43. Duarte SMB, Stefano JT, Miele L, Ponziani FR, Souza-Basqueira M, Okada LSRR, et al. Gut microbiome composition in lean patients with NASH is associated with liver damage independent of caloric intake: A prospective pilot study. Nutr Metab Cardiovasc Dis. 2018;28:369-84

44. Zhu L, Baker RD, Zhu R, Baker SS. Gut microbiota produce alcohol and contribute to NAFLD. Gut. 2016;65:1232.

45. Mandard S, Zandbergen F, Tan NS, Escher P, Patsouris D, Koenig W, et al. The direct peroxisome proliferator-activated receptor target fasting-induced adipose factor (FIAF/PGAR/ANGPTL4) is present in blood plasma as a truncated protein that is increased by fenofibrate treatment. J Biol Chem. 2004;279:34411-20.

46. Ley RE. Obesity and the human microbiome. Curr Opin Gastroenterol. 2010;26:511

47. Musso G, Gambino R, Cassader M. Interactions between gut microbiota and host metabolism predisposing to obesity and diabetes. Annu Rev Med. 2011;62:361-80.

48. Mehal WZ. The gut-liver axis: a busy two-way street. Hepatology. 2012;55:1647-9.

49. Pataky Z, Genton L, Spahr L, Lazarevic V, Terraz S, Gaïa N, et al. Impact of Hypocaloric Hyperproteic Diet on Gut Microbiota in Overweight or Obese Patients with Nonalcoholic Fatty Liver Disease: A Pilot Study. Dig Dis Sci. 2016;61:2721-31.

50. Hu QH, Zhang X, Pan Y, Li YC, Kong LD. Allopurinol, quercetin and rutin ameliorate renal NLRP3 inflammasome activation and lipid accumulation in fructose-fed rats. Biochem Pharmacol. 2012;84:113-25.

51. Gutiérrez-Salmeán G, Meaney E, Lanaspa MA, Cicerchi C, Johnson RJ, Dugar $\mathrm{S}$, et al. A randomized, placebo-controlled, double-blind study on the effects of (-)-epicatechin on the triglyceride/HDLc ratio and cardiometabolic profile of subjects with hypertriglyceridemia: Unique in vitro effects. Int $\mathbf{J}$ Cardiol. 2016;223:500-6

52. Alfonzo González GC. [Effect of thermal treatment on total dietetic fiber, soluble and insoluble contents in legumes]. Arch Latinoam Nutr. 2000;50:281-5.

53. Galisteo M, Duarte J, Zarzuelo A. Effects of dietary fibers on disturbances clustered in the metabolic syndrome. J Nutr Biochem. 2008;19:71-84.

54. Federico A, Zulli C, de Sio I, Del Prete A, Dallio M, Masarone M, et al. Focus on emerging drugs for the treatment of patients with non-alcoholic fatty liver disease. World J Gastroenterol. 2014;20:16841-57.

55. Endo J, Arita M. Cardioprotective mechanism of omega-3 polyunsaturated fatty acids. J Cardiol. 2016;67:22-7.

56. Shapiro H, Tehilla M, Attal-Singer J, Bruck R, Luzzatti R, Singer P. The therapeutic potential of long-chain omega-3 fatty acids in nonalcoholic fatty liver disease. Clin Nutr. 2011;30:6-19

57. Masterton GS, Plevris JN, Hayes PC. Review article: omega-3 fatty acids - a promising novel therapy for non-alcoholic fatty liver disease. Aliment Pharmacol Ther. 2010;31:679-92.

58. Araya J, Rodrigo R, Videla LA, Thielemann L, Orellana M, Pettinelli P, et al. Increase in long-chain polyunsaturated fatty acid $n-6 / n-3$ ratio in relation to hepatic steatosis in patients with non-alcoholic fatty liver disease. Clin Sci (Lond). 2004; $106: 635-43$.

59. Araya J, Rodrigo R, Pettinelli P, Araya AV, Poniachik J, Videla LA. Decreased liver fatty acid delta- 6 and delta- 5 desaturase activity in obese patients. Obesity (Silver Spring). 2010;18:1460-3

60. Lonardo A, Bellentani S, Argo CK, Ballestri S, Byrne CD, Caldwell SH, et al. Epidemiological modifiers of non-alcoholic fatty liver disease: Focus on high-risk groups. Dig Liver Dis. 2015;47:997-1006.

61. Yu L, Yuan M, Wang L. The effect of omega-3 unsaturated fatty acids on non-alcoholic fatty liver disease: A systematic review and meta-analysis of RCTs. Pak J Med Sci. 2017;33:1022-8.

62. Parker HM, Johnson NA, Burdon CA, Cohn JS, O'Connor HT, George J. Omega-3 supplementation and non-alcoholic fatty liver disease: a systematic review and meta-analysis. J Hepatol. 2012;56:944-51.

63. Yuan F, Wang H, Tian Y, Li Q, He L, Li N, et al. Fish oil alleviated high-fat diet-induced non-alcoholic fatty liver disease via regulating hepatic lipids metabolism and metaflammation: a transcriptomic study. Lipids Health Dis. 2016;15:20.

64. Nogueira MA, Oliveira CP, Ferreira Alves VA, Stefano JT, Rodrigues LS, Torrinhas RS, et al. Omega-3 polyunsaturated fatty acids in treating non-alcoholic steatohepatitis: A randomized, double-blind, placebo-controlled trial. Clin Nutr. 2016;35:578-86.

65. Sanyal AJ, Abdelmalek MF, Suzuki A, Cummings OW, Chojkier M, Group E-AS. No significant effects of ethyl-eicosapentanoic acid on histologic features of nonalcoholic steatohepatitis in a phase 2 trial. Gastroenterology. 2014;147:377-84.e1.

66. Scorletti E, Bhatia L, McCormick KG, Clough GF, Nash K, Hodson L, et al. Effects of purified eicosapentaenoic and docosahexaenoic acids in nonalcoholic fatty liver disease: results from the Welcome* study. Hepatology. 2014;60:1211-21.

67. Argo CK, Patrie JT, Lackner C, Henry TD, de Lange EE, Weltman AL, et al. Effects of n-3 fish oil on metabolic and histological parameters in NASH: a double-blind, randomized, placebo-controlled trial. J Hepatol. 2015;62:190-7. 
68. Duarte SM, Rezende RE, Stefano JT, Perandini LA, Dassouki T, Sa-Pinto AL, et al. Impaired aerobic capacity and cardiac autonomic control in sedentary postmenopausal women with nonalcoholic fatty liver disease (NAFLD). Journal of Hepatology. 2015;62:S733.

69. Finelli C, Tarantino G. Is there any consensus as to what diet or lifestyle approach is the right one for NAFLD patients? J Gastrointestin Liver Dis. 2012;21:293-302.

70. Nseir W, Hellou E, Assy N. Role of diet and lifestyle changes in nonalcoholic fatty liver disease. World J Gastroenterol. 2014;20:9338-44.

71. Andersen T, Gluud C, Franzmann MB, Christoffersen P. Hepatic effects of dietary weight loss in morbidly obese subjects. J Hepatol. 1991;12:224-9.

72. Yki-Järvinen H. Nutritional Modulation of Non-Alcoholic Fatty Liver Disease and Insulin Resistance. Nutrients. 2015;7:9127-38.

73. Suárez M, Boqué N, Del Bas JM, Mayneris-Perxachs J, Arola L, Caimari A Mediterranean Diet and Multi-Ingredient-Based Interventions for the Management of Non-Alcoholic Fatty Liver Disease. Nutrients. 2017;9(10).

74. Eslamparast T, Tandon P, Raman M. Dietary Composition Independent of Weight Loss in the Management of Non-Alcoholic Fatty Liver Disease. Nutrients. 2017;9(8).

75. de Wit NJ, Afman LA, Mensink M, Müller M. Phenotyping the effect of diet on non-alcoholic fatty liver disease. J Hepatol. 2012;57:1370-3.

76. Bortolotti M, Maiolo E, Corazza M, Van Dijke E, Schneiter P, Boss A, et al. Effects of a whey protein supplementation on intrahepatocellular lipids in obese female patients. Clin Nutr. 2011;30:494-8.

77. Oliveira LP, de Jesús RP, Freire TO, Oliveira CP, Castro Lyra A, Lyra LG. Possible molecular mechanisms soy-mediated in preventing and treating nonalcoholic fatty liver disease. Nutr Hosp. 2012;27:991-8.

78. González Cañete N, Durán Agüero S. [Soya isoflavones and evidences on cardiovascular protection]. Nutr Hosp. 2014;29:1271-82.

79. Catalano D, Trovato GM, Martines GF, Randazzo M, Tonzuso A. Bright liver, body composition and insulin resistance changes with nutritional intervention a follow-up study. Liver Int. 2008;28:1280-7.

80. Schwarz J, Tomé D, Baars A, Hooiveld GJ, Müller M. Dietary protein affects gene expression and prevents lipid accumulation in the liver in mice. PLoS One. 2012;7:e47303.

81. Bortolotti M, Kreis R, Debard C, Cariou B, Faeh D, Chetiveaux M, et al. High protein intake reduces intrahepatocellular lipid deposition in humans. Am J Clin Nutr. 2009;90:1002-10.

82. Theytaz F, Noguchi Y, Egli L, Campos V, Buehler T, Hodson L, et al. Effects of supplementation with essential amino acids on intrahepatic lipid concentrations during fructose overfeeding in humans. Am J Clin Nutr. 2012;96:1008-16.

83. easloffice@easloffice.eu EAftSotLEa, Liver EAftSot. EASL Clinical Practice Guidelines on nutrition in chronic liver disease. J Hepatol. 2018.

84. Fraser GE. Associations between diet and cancer, ischemic heart disease, and all-cause mortality in non-Hispanic white California Seventh-day Adventists. Am J Clin Nutr. 1999;70(3 Suppl):532S-8S

85. Fraser GE. Vegetarian diets: what do we know of their effects on common chronic diseases? Am J Clin Nutr. 2009;89:1607S-12S

86. Wang PY, Fang JC, Gao ZH, Zhang C, Xie SY. Higher intake of fruits, vegetables or their fiber reduces the risk of type 2 diabetes: A meta-analysis. J Diabetes Investig. 2016;7:56-69.

87. Larsson SC, Wolk A. Dietary fiber intake is inversely associated with stroke incidence in healthy Swedish adults. J Nutr. 2014;144:1952-5.

88. Cook LT, O’Reilly GA, Goran MI, Weigensberg MJ, Spruijt-Metz D, Davis JN Vegetable consumption is linked to decreased visceral and liver fat and improved insulin resistance in overweight Latino youth. J Acad Nutr Diet. 2014;114:1776-83.

89. Salomone F, Godos J, Zelber-Sagi S. Natural antioxidants for non-alcoholic fatty liver disease: molecular targets and clinical perspectives. Liver Int. 2016;36:5-20

90. Saquib N, Natarajan L, Rock CL, Flatt SW, Madlensky L, Kealey S, et al. The impact of a long-term reduction in dietary energy density on body weight within a randomized diet trial. Nutr Cancer. 2008;60:31-8.

91. Yang Y, Zhang D, Feng N, Chen G, Liu J, Zhu Y. Increased intake of vegetables, but not fruit, reduces risk for hepatocellular carcinoma: a meta-analysis. Gastroenterology. 2014;147:1031-42.

92. Wu QJ, Yang Y, Vogtmann E, Wang J, Han LH, Li HL, et al. Cruciferous vegetables intake and the risk of colorectal cancer: a meta-analysis of observational studies. Ann Oncol. 2013;24:1079-87.

93. Wu QJ, Xie L, Zheng W, Vogtmann E, Li HL, Yang G, et al. Cruciferous vegetables consumption and the risk of female lung cancer: a prospective study and a meta-analysis. Ann Oncol. 2013;24:1918-24.

94. Sofi F, Casini A. Mediterranean diet and non-alcoholic fatty liver disease: new therapeutic option around the corner? World J Gastroenterol. 2014;20:7339-46.

95. Zelber-Sagi S, Salomone F, Mlynarsky L. The Mediterranean dietary pattern as the diet of choice for non-alcoholic fatty liver disease: Evidence and plausible mechanisms. Liver Int. 2017;37:936-49.
96. Anderson JW, Randles KM, Kendall CW, Jenkins DJ. Carbohydrate and fiber recommendations for individuals with diabetes: a quantitative assessment and meta-analysis of the evidence. J Am Coll Nutr. 2004;23:5-17.

97. Estruch R. Anti-inflammatory effects of the Mediterranean diet: the experience of the PREDIMED study. Proc Nutr Soc. 2010;69:333-40.

98. Scalbert A, Williamson G. Dietary intake and bioavailability of polyphenols. J Nutr. 2000;130(8S Suppl):2073S-85S

99. Han JM, Jo AN, Lee SM, Bae HS, Jun DW, Cho YK, et al. Associations between intakes of individual nutrients or whole food groups and non-alcoholic fatty liver disease among Korean adults. J Gastroenterol Hepatol. 2014;29:1265-72.

100. Shi L, Liu ZW, Li Y, Gong C, Zhang H, Song LJ, et al. The prevalence of nonalcoholic fatty liver disease and its association with lifestyle/dietary habits among university faculty and staff in Chengdu. Biomed Environ Sci. 2012;25: 383-91.

101. Grosso G, Mistretta A, Frigiola A, Gruttadauria S, Biondi A, Basile F, et al Mediterranean diet and cardiovascular risk factors: a systematic review. Crit Rev Food Sci Nutr. 2014;54:593-610.

102. Estruch R, Ros E, Salas-Salvadó J, Covas MI, Corella D, Arós F, et al. Primary prevention of cardiovascular disease with a Mediterranean diet. N Engl J Med. 2013;368:1279-90.

103. Salas-Salvadó J, Bulló M, Estruch R, Ros E, Covas MI, Ibarrola-Jurado N, et al. Prevention of diabetes with Mediterranean diets: a subgroup analysis of a randomized trial. Ann Intern Med. 2014;160:1-10

104. Uribarri J, del Castillo MD, de la Maza MP, Filip R, Gugliucci A, Luevano-Contreras C, et al. Dietary advanced glycation end products and their role in health and disease. Adv Nutr. 2015;6:461-73.

105. Koschinsky T, He CJ, Mitsuhashi T, Bucala R, Liu C, Buenting C, et al. Orally absorbed reactive glycation products (glycotoxins): an environmental risk factor in diabetic nephropathy. Proc Natl Acad Sci U S A. 1997;94:6474-9.

106. Kellow NJ, Savige GS. Dietary advanced glycation end-product restriction for the attenuation of insulin resistance, oxidative stress and endothelial dysfunction: a systematic review. Eur J Clin Nutr. 2013;67:239-48.

107. Sekiya M, Yahagi N, Matsuzaka T, Najima Y, Nakakuki M, Nagai R, et al Polyunsaturated fatty acids ameliorate hepatic steatosis in obese mice by SREBP-1 suppression. Hepatology. 2003:38:1529-39.

108. Levy JR, Clore JN, Stevens W. Dietary n-3 polyunsaturated fatty acids decrease hepatic triglycerides in Fischer 344 rats. Hepatology. 2004;39:608-16.

109. Sofi F, Abbate R, Gensini GF, Casini A. Accruing evidence on benefits of adherence to the Mediterranean diet on health: an updated systematic review and meta-analysis. Am J Clin Nutr. 2010;92:1189-96.

110. de Lorgeril M, Salen P, Martin JL, Monjaud I, Delaye J, Mamelle N. Mediterranean diet, traditional risk factors, and the rate of cardiovascular complications after myocardial infarction: final report of the Lyon Diet Heart Study. Circulation. 1999;99:779-85

111. Romero-Gómez M, Zelber-Sagi S, Trenell M. Treatment of NAFLD with diet, physical activity and exercise. J Hepatol. 2017;67:829-46.

112. Madero M, Arriaga JC, Jalal D, Rivard C, McFann K, Pérez-Méndez O, et al The effect of two energy-restricted diets, a low-fructose diet versus a moderate natural fructose diet, on weight loss and metabolic syndrome parameters: a randomized controlled trial. Metabolism. 2011;60:1551-9.

113. Ascha MS, Hanouneh IA, Lopez R, Tamimi TA, Feldstein AF, Zein NN. The incidence and risk factors of hepatocellular carcinoma in patients with nonalcoholic steatohepatitis. Hepatology. 2010;51:1972-8.

114. Dunn W, Xu R, Schwimmer JB. Modest wine drinking and decreased prevalence of suspected nonalcoholic fatty liver disease. Hepatology. 2008;47:1947-54.

115. Trovato FM, Catalano D, Martines GF, Pace P, Trovato GM. Mediterranean diet and non-alcoholic fatty liver disease: the need of extended and comprehensive interventions. Clin Nutr. 2015;34:86-8.

116. Bozzetto L, Prinster A, Annuzzi G, Costagliola L, Mangione A, Vitelli A, et al. Liver fat is reduced by an isoenergetic MUFA diet in a controlled randomized study in type 2 diabetic patients. Diabetes Care. 2012;35:1429-35.

117. Ryan MC, Itsiopoulos C, Thodis T, Ward G, Trost N, Hofferberth S, et al. The Mediterranean diet improves hepatic steatosis and insulin sensitivity in individuals with non-alcoholic fatty liver disease. J Hepatol. 2013;59:138-43.

118. European Association for the Study of the Liver; European Association for the Study of Diabetes; European Association for the Study of Obesity. EASL-EASD-EASO Clinical Practice Guidelines for the management of non-alcoholic fatty liver disease. J Hepatol. 2016;64:1388-402.

119. Hiramatsu T, Tajima O, Uezono K, Tabata S, Abe H, Ohnaka K, et al. Coffee consumption, serum $\gamma$-glutamyltransferase, and glucose tolerance status in middle-aged Japanese men. Clin Chem Lab Med. 2013;51:1233-9.

120. Ruhl CE, Everhart JE. Coffee and caffeine consumption reduce the risk of elevated serum alanine aminotransferase activity in the United States. Gastroenterology. 2005; $128: 24-32$ 
121. Molloy JW, Calcagno CJ, Williams CD, Jones FJ, Torres DM, Harrison SA. Association of coffee and caffeine consumption with fatty liver disease, nonalcoholic steatohepatitis, and degree of hepatic fibrosis. Hepatology. 2012;55:429-36.

122. Corrao G, Zambon A, Bagnardi V, D’Amicis A, Klatsky A, Group CS. Coffee, caffeine, and the risk of liver cirrhosis. Ann Epidemiol. 2001;11:458-65.

123. Gallus S, Tavani A, Negri E, La Vecchia C. Does coffee protect against liver cirrhosis? Ann Epidemiol. 2002;12:202-5.

124. Tverdal A, Skurtveit S. Coffee intake and mortality from liver cirrhosis. Ann Epidemiol. 2003;13:419-23.

125. Setiawan VW, Wilkens LR, Lu SC, Hernandez BY, Le Marchand L, Henderson BE. Association of coffee intake with reduced incidence of liver cancer and death from chronic liver disease in the US multiethnic cohort. Gastroenterology. 2015;148:118-25; quiz e15.

126. Saab S, Mallam D, Cox GA, Tong MJ. Impact of coffee on liver diseases: a systematic review. Liver Int. 2014;34:495-504.

127. Bravi F, Bosetti C, Tavani A, Gallus S, La Vecchia C. Coffee reduces risk for hepatocellular carcinoma: an updated meta-analysis. Clin Gastroenterol Hepatol. 2013;11:1413-21.el.

128. He P, Noda Y, Sugiyama K. Suppression of lipopolysaccharide-induced liver injury by various types of tea and coffee in D-galactosamine-sensitized rats. Biosci Biotechnol Biochem. 2001;65:670-3.

129. Huber WW, Scharf G, Rossmanith W, Prustomersky S, Grasl-Kraupp B, Peter $\mathrm{B}$, et al. The coffee components kahweol and cafestol induce gamma-glutamylcysteine synthetase, the rate limiting enzyme of chemoprotective glutathione synthesis, in several organs of the rat. Arch Toxicol. 2002;75:685-94.

130. Lee KG, Mitchell A, Shibamoto T. Antioxidative activities of aroma extracts isolated from natural plants. Biofactors. 2000;13:173-8.

131. Freedman ND, Park Y, Abnet CC, Hollenbeck AR, Sinha R. Association of coffee drinking with total and cause-specific mortality. N Engl J Med. 2012;366: 1891-904.

132. Torres DM, Harrison SA. Is it time to write a prescription for coffee? Coffee and liver disease. Gastroenterology. 2013;144:670-2.

133. Anty R, Marjoux S, Iannelli A, Patouraux S, Schneck AS, Bonnafous S, et al Regular coffee but not espresso drinking is protective against fibrosis in a cohor mainly composed of morbidly obese European women with NAFLD undergoing bariatric surgery. J Hepatol. 2012;57:1090-6.

134. Urgert R, Meyboom S, Kuilman M, Rexwinkel H, Vissers MN, Klerk M, et al. Comparison of effect of cafetière and filtered coffee on serum concentrations of liver aminotransferases and lipids: six month randomised controlled trial. BMJ. 1996;313:1362-6.

135. Lee KJ, Choi JH, Jeong HG. Hepatoprotective and antioxidant effects of the coffee diterpenes kahweol and cafestol on carbon tetrachloride-induced liver damage in mice. Food Chem Toxicol. 2007;45:2118-25.

136. Veronese N, Notarnicola M, Cisternino AM, Reddavide R, Inguaggiato R, Guerra V, et al. Coffee Intake and Liver Steatosis: A Population Study in a Mediterranean Area. Nutrients. 2018;10(1).

137. Kerimi A, Williamson G. The cardiovascular benefits of dark chocolate. Vascul Pharmacol. 2015;71:11-5.

138. Loffredo L, Del Ben M, Perri L, Carnevale R, Nocella C, Catasca E, et al. Effects of dark chocolate on NOX-2-generated oxidative stress in patients with non-alcoholic steatohepatitis. Aliment Pharmacol Ther. 2016;44:279-86.

139. Loffredo L, Baratta F, Ludovica P, Battaglia S, Carnevale R, Nocella C, et al. Effects of dark chocolate on endothelial function in patients with non-alcoholic steatohepatitis. Nutr Metab Cardiovasc Dis. 2017;28:143-9.

140. Violi F, Basili S, Nigro C, Pignatelli P. Role of NADPH oxidase in atherosclerosis. Future Cardiol. 2009;5:83-92

141. De Minicis S, Bataller R, Brenner DA. NADPH oxidase in the liver: defensive, offensive, or fibrogenic? Gastroenterology. 2006;131:272-5.
142. Lee Y, Berryman CE, West SG, Chen CO, Blumberg JB, Lapsley KG, et al. Effects of Dark Chocolate and Almonds on Cardiovascular Risk Factors in Overweight and Obese Individuals: A Randomized Controlled-Feeding Trial. J Am Heart Assoc. 2017;6(12).

143. Wiese M, Bashmakov Y, Chalyk N, Nielsen DS, Krych Ł, Kot W, et al. Prebiotic Effect of Lycopene and Dark Chocolate on Gut Microbiome with Systemic Changes in Liver Metabolism, Skeletal Muscles and Skin in Moderately Obese Persons. Biomed Res Int. 2019;2019:4625279.

144. Chalasani N, Younossi Z, Lavine JE, Charlton M, Cusi K, Rinella M, et al. The diagnosis and management of nonalcoholic fatty liver disease: Practice guidance from the American Association for the Study of Liver Diseases. Hepatology. 2018;67:328-57.

145. Sanyal AJ, Chalasani N, Kowdley KV, McCullough A, Diehl AM, Bass NM, et al. Pioglitazone, vitamin E, or placebo for nonalcoholic steatohepatitis. N Engl J Med. 2010;362:1675-85.

146. de Oliveira CP, Stefano JT, de Siqueira ER, Silva LS, de Campos Mazo DF, Lima VM, et al. Combination of $\mathrm{N}$-acetylcysteine and metformin improves histological steatosis and fibrosis in patients with non-alcoholic steatohepatitis. Hepatol Res. 2008;38:159-65.

147. Thong-Ngam D, Samuhasaneeto S, Kulaputana O, Klaikeaw N. N-acetylcysteine attenuates oxidative stress and liver pathology in rats with non-alcoholic steatohepatitis. World J Gastroenterol. 2007;13:5127-32.

148. Caiazzo R, Lassailly G, Leteurtre E, Baud G, Verkindt H, Raverdy V, et al. Rouxen-Y gastric bypass versus adjustable gastric banding to reduce nonalcoholic fatty liver disease: a 5-year controlled longitudinal study. Ann Surg. 2014;260:893-8; discussion 8-9.

149. Lassailly G, Caiazzo R, Buob D, Pigeyre M, Verkindt H, Labreuche J, et al. Bariatric Surgery Reduces Features of Nonalcoholic Steatohepatitis in Morbidly Obese Patients. Gastroenterology. 2015;149:379-88; quiz e15-6.

150. Bäckhed F, Ding H, Wang T, Hooper LV, Koh GY, Nagy A, et al. The gut microbiota as an environmental factor that regulates fat storage. Proc Natl Acad Sci U S A. 2004;101:15718-23.

151. Soares JB, Pimentel-Nunes P, Roncon-Albuquerque R, Leite-Moreira A. The role of lipopolysaccharide/toll-like receptor 4 signaling in chronic liver diseases. Hepatol Int. 2010;4:659-72.

152. Sanders ME, Merenstein DJ, Reid G, Gibson GR, Rastall RA. Probiotics and prebiotics in intestinal health and disease: from biology to the clinic. Nat Rev Gastroenterol Hepatol. 2019.

153. Mofidi F, Poustchi H, Yari Z, Nourinayyer B, Merat S, Sharafkhah M, et al. Synbiotic supplementation in lean patients with non-alcoholic fatty liver disease: a pilot, randomised, double-blind, placebo-controlled, clinical trial. Br J Nutr. 2017;117:662-8

154. Cho MS, Kim SY, Suk KT, Kim BY. Modulation of gut microbiome in nonalcoholic fatty liver disease: pro-, pre-, syn-, and antibiotics. J Microbiol. 2018;56:855-67.

155. Mokhtari Z, Gibson DL, Hekmatdoost A. Nonalcoholic Fatty Liver Disease, the Gut Microbiome, and Diet. Adv Nutr. 2017;8:240-52.

156. Wong VW, Won GL, Chim AM, Chu WC, Yeung DK, Li KC, et al. Treatment of nonalcoholic steatohepatitis with probiotics. A proof-of-concept study. Ann Hepatol. 2013;12:256-62

157. Ma X, Hua J, Li Z. Probiotics improve high fat diet-induced hepatic steatosis and insulin resistance by increasing hepatic NKT cells. J Hepatol. 2008:49:821-30.

158. Donato KA, Gareau MG, Wang YJ, Sherman PM. Lactobacillus rhamnosus GG attenuates interferon-\{gamma $\}$ and tumour necrosis factor-alpha-induced barrier dysfunction and pro-inflammatory signalling. Microbiology. 2010;156(Pt 11):3288-97.

159. Shin HS, Park SY, Lee dK, Kim SA, An HM, Kim JR, et al. Hypocholesterolemic effect of sonication-killed Bifidobacterium longum isolated from healthy adult Koreans in high cholesterol fed rats. Arch Pharm Res. 2010;33:1425-31. 